\title{
Hierarchical porous activated carbon for supercapacitor derived from corn stalk core by potassium hydroxide activation
}

Yuhe Cao ${ }^{\text {a }}$, Keliang Wang a , Xiaomin Wang ${ }^{\text {a }}$, Zhengrong Gu ${ }^{\text {a,* }}$, Qihua Fan ${ }^{\text {b }}$, William

Gibbons ${ }^{c}$, James D. Hoefelmeyer ${ }^{\text {d }}$, Parashu Ram Kharel ${ }^{\mathrm{e}}$, Maheshwar Shrestha ${ }^{\mathrm{b}}$

a Agricultural and Biosystems Engineering Department, South Dakota State University, Brookings, SD, USA

${ }^{\mathrm{b}}$ Electrical Engineering and Computer Science Department, South Dakota State University, USA

${ }^{\mathrm{c}}$ Department of Biology and Microbiology, South Dakota State University, Brookings, SD, USA

${ }^{\mathrm{d}}$ Chemistry department, University of South Dakota, Vermillion, SD, USA

${ }^{\mathrm{e}}$ Physics Department, South Dakota State University, Brookings, SD, USA

\section{*Correspondence:}

Zhengrong Gu

North Campus Drive 1400, Agricultural and Biosystems Engineering, South Dakota State University, Brookings, SD 57007, USA

Tel: +1-605-688-5372 Fax: +1-605-688-6764 Email: Zhengrong.gu@sdstate.edu 


\section{$\underline{\text { Abbreviations }}$}

AC: activated carbon

BET: Brunauer-Emmett-Teller

CSC: corn stalk core

CSC-600: activated carbon prepared from corn stalk core at $600{ }^{\circ} \mathrm{C}$

CSC-700: activated carbon prepared from corn stalk core at $700{ }^{\circ} \mathrm{C}$

CSC-800: activated carbon prepared from corn stalk core at $800{ }^{\circ} \mathrm{C}$

CSC-900: activated carbon prepared from corn stalk core at $900{ }^{\circ} \mathrm{C}$

CV: cyclic voltammetry

DFT: density functional theory

EDS: energy dispersive spectroscopy

EDLC: electrochemical double layer capacitor

EIS: electrochemical impedance spectra

ESR: equivalent series resistance ${ }^{1}$

STEM: scanning transmission electron microscopy

\section{Abstract}

Hierarchical porous activated carbon (AC) was obtained from corn stalk pith with a hierarchical macroporous nature, which is composed of cells of soft and spongy texture. The high specific surface area $\left(2495 \mathrm{~m}^{2} \mathrm{~g}^{-1}\right)$ of the activated carbon (AC) was produced by the activation of corn stalk core (CSC) using potassium hydroxide at $700{ }^{\circ} \mathrm{C}$. SEM, TEM and XRD were used to test the microstructure and crystallographic orientation of the carbon samples. The cyclic voltammetry, galvanostatic charge/discharge and electrochemical impedance spectroscopy were measured based on CSC-700. This sample had relatively low inner resistance of $1.0 \Omega$. The specific capacitance was $323 \mathrm{~F} \mathrm{~g}^{-1}$ in $6 \mathrm{~mol} \mathrm{~L}^{-1} \mathrm{KOH}$ electrolyte at a current density of $0.1 \mathrm{~A} \mathrm{~g}^{-1}$, and it still maintained very good cyclic stability with capacitance retention ratio of 97.9\% (from 265.0 to $262.4 \mathrm{~F} \mathrm{~g}^{-1}$ ) at current density of $1.0 \mathrm{~A} \mathrm{~g}^{-1}$ for 1000 cycles.

Key words: Supercapacitors; Corn stalk core; $\mathrm{KOH}$; Activated carbon; Hierarchical porous carbon 


\subsection{Introduction}

Supercapacitor is a novel energy storage component, which has become one of highlights in the field of energy research due to their high power density and long life cycle [1-3]. As an intermediate energy storage devices, it shows higher energy density than traditional capacitors and higher power density than secondary batteries [4], which can work as a supplement to batteries for high power demand of vehicles in starting, accelerating and climbing [1]. There are two types of supercapacitors based on their energy storage mechanism: electrochemical double layer capacitor (EDLC) and pseudocapacitor. The energy storage in EDLC is mainly based on electrostatic attraction to generate charge accumulation in the electric double layer, which is formed at the electrode/electrolyte interface [1]. Capacitance in EDLC, mostly comes from ion storage in the porous electrodes, while in pseudocapacitance it comes from the fast reversible redox reactions in the electrodes $[4,5]$.

Conductive polymers [6] and transition metal oxide [7] are the attractive choices for electrode materials. However, their low surface area, poor conductivity are preventing their application commercially. Porous carbon materials are widely used as electrodes owing to their high surface area, well-developed pore-size distribution, which can be adapted to the size of the electrolyte ions, high conductivity, and good physicochemical stability [8]. AC, carbon nanotubes, graphene and composites of these have been used as the electrode materials. AC materials can possess higher market potential due to the lower cost than carbon nanotubes and graphene [4]. In addition, AC surfaces can be decorated with functional groups easily [9, 10], which can modify the double-layer capacitance $[11,12]$. Traditional AC electrode materials were mainly produced from coal, petroleum, or their derived products through a series of activation procedures [1]. Because of finite reserves of fossil fuels and environmental concern [13, 14], 
more and more researchers have explored alternative resources for preparing AC. Biomass wastes are very cheap and easily available, which are potential raw materials for the preparation of porous carbons with good electrochemical capacitive performance. Over recent years a considerable amount of literature has been published on the usage of biomass based porous materials as electrode materials [15-21].

Corn stalk is an abundant agricultural waste, which is renewable and low cost. It is made up of a cortex and a core, and the cortex is mainly made up of cellulose and lignin and the CSC is mainly hemi-cellulose and a little lignin and cellulose [22]. Different parts of the biomass would produce different texture morphology. CSC is like a foam, which is porous. This natural porous structure can potentially generate hierarchical porous structure, which provides carbon with large surface for the electron transfer and short way for ion diffusion in carbon matrix.

In this study, CSC was employed as a precursor to prepare nanoporous AC. Based on the spongy texture of the corn stalk pith, we were expecting to obtain carbon materials with a relatively high surface area and hierarchical porous structure using $\mathrm{KOH}$ as the activating agent [23]. Graphitized activated carbon exhibited large specific surface area with superior capacitive performance. Based on the former results we obtained [24, 25], we tried to generate graphitic carbons from cornstalk core by using $\mathrm{Ni}\left(\mathrm{NO}_{3}\right)_{2}$. Conventional graphitization requires high temperature up to $2500{ }^{\circ} \mathrm{C}$, while the graphitization temperature can be led to below $1000{ }^{\circ} \mathrm{C}$ with transition metal (Fe, Co, or $\mathrm{Ni}$ ) served as catalyst [25]. Ni catalytic graphitization could be an effective way to produce graphitic carbon. To our knowledge, little previous researches focused on this respect. The electrochemical properties were characterized by different instruments and the relationships between the specific capacitance and pore properties were analyzed. 


\subsection{Preparation of ACs}

The corn stalk was collected from a farm located in Brookings, South Dakota, USA. The leaves and husks were manually stripped from the stalks and then the stalk sample was air dried. After air drying, the cortex was further peeled away to leave the core. The core was mixed with $\mathrm{Ni}\left(\mathrm{NO}_{3}\right)_{2} \cdot 6 \mathrm{H}_{2} \mathrm{O}$ solution at impregnation mass ratio of $1: 10\left(\mathrm{Ni}\left(\mathrm{NO}_{3}\right)_{2} \cdot 6 \mathrm{H}_{2} \mathrm{O}\right.$ : core). The mixture was dried at $105{ }^{\circ} \mathrm{C}$ for $24 \mathrm{~h}$. Then the CSC were cut into pieces of $25 \mathrm{~mm}$ length and preliminary carbonized at $400{ }^{\circ} \mathrm{C}$ for $1 \mathrm{~h}$ in muffle furnace in $\mathrm{N}_{2}$ atmosphere $\left(\mathrm{N}_{2}\right.$ flow rate is 500 $\left.\mathrm{ml} \mathrm{min}{ }^{-1}\right)$. The preliminary carbonized material was mixed with $\mathrm{KOH}$ solution at impregnation mass ratio of 1:4.2 (KOH pallet: Char). This mixture was then put into oven and dried at $105{ }^{\circ} \mathrm{C}$ for $24 \mathrm{~h}$. After that the activation was carried out at $600,700,800$ and $900{ }^{\circ} \mathrm{C}$ separately for $1 \mathrm{~h}$ with the protection of $500 \mathrm{ml} \mathrm{min}^{-1} \mathrm{~N}_{2}$ flow. The temperature ramping rate was $20^{\circ} \mathrm{C} / \mathrm{min}$ for all the preliminary carbonizations and activations. The obtained samples were cooled down in tube furnace in the same $\mathrm{N}_{2}$ atmosphere. The ACs were further purified in $6 \mathrm{M} \mathrm{HCl}$ at $110{ }^{\circ} \mathrm{C}$ within the hydrothermal reactor for $1 \mathrm{~h}$. then the ACs were washed with deionized water under vacuum filtration until the $\mathrm{pH}$ value of the permeate was $\sim 7$. Finally, the washed $\mathrm{AC}$ was dried in a vacuum oven at $105{ }^{\circ} \mathrm{C}$ overnight. CSC derived ACs are denoted as CSC-600, CSC-700, CSC800, and CSC-900 based on the activation temperature.

\subsection{Characterizations of ACs}

Isothermal adsorption analysis with $\mathrm{N}_{2}$ were carried out at $77 \mathrm{~K}$ (liquid nitrogen bath), using an ASAP 2020 Micropore Analyzer. The specific surface areas were calculated using the Brunauer-Emmett-Teller (BET) equation. The total pore volume was determined at relative pressure 0.995 . The micropore and mesopore volume and the pore size distribution were determined by the density functional theory (DFT) for samples based on the $\mathrm{N}_{2}$ isotherm 
adsorption data. The structure of activated carbon was also characterized with TEM (Hitachi H$7000 \mathrm{FA}$, operating at $200 \mathrm{kV}$ ) and their elemental compositions were determined by Energy Dispersive Spectroscopy (EDS) (OXFORD X-MaxN), SEM (HITACHI S-3400N, operating at 5 $\mathrm{kV})$ and XRD (Rigaku D/Max Ultima, operating with filtered $\mathrm{Cu}-\mathrm{K}_{\alpha}$ radiation $(\lambda=1.54 \AA)$ at 15 $\mathrm{mA}$ and $30 \mathrm{kV})$.

\subsection{Supercapacitor Fabrication and Electrochemical characterization}

The supercapacitors were assembled as the general [4]. The electrodes were prepared by pressing the slurry of AC, carbon black (conducting material from Fisher scientific) and PTFE (binder) with a mass ration of 8:1:1 on nickel foam. Mass of pellets varied from 6 to $7 \mathrm{mg}$. Masses of CSC-600, CSC-700, CSC-800 and CSC-900 electrodes are 6.2/6.4, 6.6/6.8, 6.1/6.2 and 6.8/6.9 mg, respectively. The geometrical surface area of the AC electrode used was $1 \mathrm{~cm}^{2}$ and the medium thickness was $\sim 100 \mu \mathrm{m}$. Two-electrode sandwich-type cells were built using a stainless coin cell (2032) with a microporous PP separator clegard-3501 between the electrodes. Meanwhile, the electrolytic medium is $6 \mathrm{~mol} \mathrm{~L}^{-1} \mathrm{KOH}$. Two-electrode sandwich-type cells supercapacitors were assembled in the argon protected glove box.

Cyclic voltammetry (scan rate from 5 to $300 \mathrm{mV} \mathrm{s}^{-1}$ ) and galvanostatic charge/discharge cycling (current density load from $100 \mathrm{~mA} \mathrm{~g}^{-1}$ to $5 \mathrm{~A} \mathrm{~g}^{-1}$ ) were performed using a SP-150 multichannel potentiostat-galvanostat-EIS (Biologic, France). The electrical conductivity of the carbon materials was also measured through the impedance spectroscopy (i.e. frequency response analysis yields over the frequency ranging from $0.1 \mathrm{~Hz}$ to $100,000 \mathrm{~Hz}$ with potential amplitude of $5 \mathrm{mV}$ ) with a SP-150 multichannel potentiostat-galvanostat-EIS (Biologic, France). And galvanostatic charge/discharge cycling was performed in Neware battery test systems. The specific capacitance of the electrode was calculated using equation (1) [26] 


$$
C=\frac{2 I \Delta t}{m \Delta V}
$$

here, $I$ is the discharge current density, $\Delta \mathrm{t}$ is the corresponding discharge time, $\mathrm{m}$ is the mass of active materials on single electrode and $\Delta \mathrm{V}$ is the total corresponding potential change.

\subsection{Results and discussion}

\subsection{Physiochemical characterization of ACs}

The pore structure and the surface area parameters were obtained by the $\mathrm{N}_{2}$ adsorption method, while the micropore volume was determined using DFT. Fig. 1A shows nitrogen adsorption-desorption isotherms at $77 \mathrm{~K}$ for four AC samples having $\mathrm{S}_{\mathrm{BET}}$ of 1597, 2495, 2452 and $1485 \mathrm{~m}^{2} \mathrm{~g}^{-1}$ (Table 1), respectively. CSC-600, CSC-700 and CSC-800 showed type I nitrogen isotherms at $77 \mathrm{~K}$, according to the IUPAC classification [27], thus characterizing microporous materials. CSC-900 showed a hysteresis loop, which is a typical type IV isotherm, indicating a large amount of mesopores [27]. CSC-800 get the highest $\mathrm{N}_{2}$ adsorption among those ACs due to the highest BET surface area and largest total pore volume $\left(1.31 \mathrm{~cm}^{3} \mathrm{~g}^{-1}\right.$, Table 1). The isotherms presented a sharp increase of nitrogen uptake at very low relative pressure and an almost horizontal plateau for CSC-700 and CSC-800, which presented a higher quantity adsorption due to the micropores than CSC-600 and CSC-900. CSC-900 shows larger adsorption-desorption hysteresis cycle than the other three samples in Fig. 1A, which indicates that CSC-900 has more mesopores $\left(0.75 \mathrm{~cm}^{3} \mathrm{~g}^{-1}\right)$ than CSC-600 $\left(0.06 \mathrm{~cm}^{3} \mathrm{~g}^{-1}\right), \mathrm{CSC}-700(0.25$ $\left.\mathrm{cm}^{3} \mathrm{~g}^{-1}\right)$ and CSC-800 $\left(0.63 \mathrm{~cm}^{3} \mathrm{~g}^{-1}\right)$ in Table 1. Fig. 1B shows the pore size distributions for the four ACs. Most of the pores from CSC-600 were smaller than $3 \mathrm{~nm}$. While the pore width range continued to increase with the temperature increasing ( $<4 \mathrm{~nm}$ for CSC-700, $<5 \mathrm{~nm}$ for CSC-800 and $<10 \mathrm{~nm}$ for CSC-900). 
There were many chemical reactions during the $\mathrm{KOH}$ activation (from equation (2) to (10)) [28]. $\mathrm{K}_{2} \mathrm{CO}_{3}$ forms at about $400{ }^{\circ} \mathrm{C}$. $\mathrm{KOH}$ is completely consumed and changed into $\mathrm{K}_{2} \mathrm{CO}_{3}$ at about $600{ }^{\circ} \mathrm{C}$. Many micropores were generated at $600{ }^{\circ} \mathrm{C}$ for CSC-600, while a small amount of mesopores $\left(0.06 \mathrm{~cm}^{3} \mathrm{~g}^{-1}\right.$, Table 1$)$ formed simultaneously. The as-formed $\mathrm{K}_{2} \mathrm{CO}_{3}$ in equation (5) and (6), significantly decomposing into $\mathrm{CO}_{2}$ and $\mathrm{K}_{2} \mathrm{O}$ at temperatures higher than $700{ }^{\circ} \mathrm{C}$ (equation (7)). Micropores were continued to develop when temperature increased from 600 to $700{ }^{\circ} \mathrm{C}$. CSC-700 obtained $0.75 \mathrm{~cm}^{3} \mathrm{~g}^{-1}$ micorpores, and pores smaller than $1.1 \mathrm{~nm}$ increased from 0.37 (CSC-600) to $0.40 \mathrm{~cm}^{3} \mathrm{~g}^{-1}$. Meanwhile, some more mesopores $\left(0.25 \mathrm{~cm}^{3} \mathrm{~g}^{-1}\right.$, Table 1) were created by stronger etching and expanding from decomposition of $\mathrm{K}_{2} \mathrm{CO}_{3}$. When the temperature increased into $800{ }^{\circ} \mathrm{C}, \mathrm{K}_{2} \mathrm{CO}_{3}$ almost completely disappeared. The resulting $\mathrm{CO}_{2}$ can be further reduced by carbon to form $\mathrm{CO}$ at higher temperature. The $\mathrm{K}$ compounds $\left(\mathrm{K}_{2} \mathrm{O}\right.$ and $\mathrm{K}_{2} \mathrm{CO}_{3}$ ) also can be reduced by carbon to produce metallic $\mathrm{K}$ at temperature 800 and $900{ }^{\circ} \mathrm{C}$. the as-prepared $\mathrm{K}$, efficiently intercalating into the carbon lattices of the carbon matrix during the activation, results in the expansion of the carbon lattices [28]. Pores were still developing with the temperature increasing. However, the micropores decreased due to intensive erosion. Hence, micropore volume of CSC-800 decreased to $0.65 \mathrm{~cm}^{3} \mathrm{~g}^{-1}$ and pores smaller than $1.1 \mathrm{~nm}$ decreased to $0.34 \mathrm{~cm}^{3} \mathrm{~g}^{-1}$. The CSC-900 gained the least micropore $\left(0.26 \mathrm{~cm}^{3} \mathrm{~g}^{-1}\right)$ and largest mesopore $\left(0.75 \mathrm{~cm}^{3} \mathrm{~g}^{-1}\right)$ volumes.

$$
\begin{aligned}
& 2 \mathrm{KOH} \rightarrow \mathrm{K}_{2} \mathrm{O}+\mathrm{H}_{2} \mathrm{O} \\
& \mathrm{C}+\mathrm{H}_{2} \mathrm{O} \rightarrow \mathrm{CO}+\mathrm{H}_{2} \\
& \mathrm{CO}+\mathrm{H}_{2} \mathrm{O} \rightarrow \mathrm{CO}_{2}+\mathrm{H}_{2} \\
& \mathrm{CO}_{2}+\mathrm{K}_{2} \mathrm{O} \rightarrow \mathrm{K}_{2} \mathrm{CO}_{3}
\end{aligned}
$$




$$
\begin{aligned}
& 6 \mathrm{KOH}+2 \mathrm{C} \rightarrow 2 \mathrm{~K}+3 \mathrm{H}_{2}+2 \mathrm{~K}_{2} \mathrm{CO}_{3} \\
& \mathrm{~K}_{2} \mathrm{CO}_{3} \rightarrow \mathrm{CO}_{2}+\mathrm{K}_{2} \mathrm{O} \\
& \mathrm{CO}_{2}+\mathrm{C} \rightarrow 2 \mathrm{CO} \\
& \mathrm{K}_{2} \mathrm{CO}_{3}+2 \mathrm{C} \rightarrow 2 \mathrm{~K}+3 \mathrm{CO} \\
& \mathrm{C}+\mathrm{K}_{2} \mathrm{O} \rightarrow 2 \mathrm{~K}+\mathrm{CO}
\end{aligned}
$$

Based on the above observations and discussions, $\mathrm{KOH}$ activation of carbon can give different pore distributions under different temperature. Higher temperature can generate more large pores (mesopores), and the order of average pore diameter was CSC-600 $(1.89 \mathrm{~nm})<$ CSC$700(1.97 \mathrm{~nm})<$ CSC-800 $(2.31 \mathrm{~nm})<$ CSC-900 $(3.36 \mathrm{~nm})$ for these AC samples (Table 1). The morphology of the pores can be seen from Fig. S1 (A-D). The pore size become larger gradually with the temperature increasing. High temperature increased the degree of graphitization (Fig. 3A-B) and cut down porosity, therefore CSC-900 displayed lower specific surface area of 1485 $\mathrm{m}^{2} \mathrm{~g}^{-1}$.

The morphology and microstructure of the CSC-700 was characterized by SEM and TEM. The distinctive microstructures and the complex three-dimensional porous structure of CSC-700 are shown in Fig. 2A. Fig. 2(B-D) shows different scale bar images of CSC-700. It indicates that the carbon constituted of narrow micropores (ultramicropores), secondary micropores (supermicropores, pore diameter is from $0.7 \mathrm{~nm}$ to $2.0 \mathrm{~nm}$ ) and mesopores (from $2.0 \mathrm{~nm}$ to 50.0 nm) [29]. These pores generated high specific surface area, which can significantly provide the chance contacting between electrode materials and electrolyte, resulting in the increase of double-layer capacitance. The micropores participate in charge storage process of supercapacitors by providing abundant adsorbing sites for the ions [30]. The mesopore (2-50 nm) 
channels facilitate the electrolyte ion migration in the material, a noticeable volume of micropores $(<2 \mathrm{~nm})$ can provide abundant adsorbing sites for the ions [30]. There are also a lot of large pores $(>50 \mathrm{~nm})$ on the CSC-700, as is shown in Fig. S1 (E-F). These pores can potentially accelerate the ion migration.

The crystalline properties of ACs were also characterized by X-ray diffraction. Fig. 3A illustrates the X-ray diffraction profiles of the activated carbons prepared at different temperatures; these carbons had been thoroughly washed. CSC-600 and CSC-700 exhibit very broad diffraction peaks and the absence of a sharp peak reveals a predominantly amorphous structure [31]. While the amorphous structure of the activated carbon transformed into a structure of greater crystallinity at higher temperatures. The sharp, narrow peak at $26^{\circ}$ in the spectrum for CSC-800 and CSC-900 indicates the presence of a highly graphitized fractions in the activated carbon samples [32]. Typically, in a crystalline carbonaceous structure, such as graphite, the interlayer distance between two adjacent carbon sheets is $0.335 \mathrm{~nm}$ [31]. In this study, the peak at $2 \theta=26^{\circ}$ corresponds to an interlayer distance of $0.338 \mathrm{~nm}$, which is quite similar to that of graphite [31]. At $900{ }^{\circ} \mathrm{C}$, the peak at $26^{\circ}$ becomes pretty sharp, indicating a highly ordered and crystallized structure. It suggests that higher temperature could generate more crystalline carbons with nickel as catalyst, which contributed to the graphitization $[33,34]$. As is shown in Fig. S2, graphite-liked pieces (in the red circles) were obtained for CSC-900. Based on these observations, it indicates that the less ordered components were burned off at a higher activation temperature, resulting in a reduction of the amorphous structure.

The Raman spectra were shown in Fig. 3B. The featured D-band and G-band peaks were displayed in both samples. The D-band located at $1340 \mathrm{~cm}^{-1}$ was attributed to the disordered graphite with $\mathrm{A}_{1 \mathrm{~g}}$ symmetry. The G-band centered at $1580 \mathrm{~cm}^{-1}$ corresponded to the first-order 
scattering of the $\mathrm{E}_{2 \mathrm{~g}}$ mode of $\mathrm{sp}^{2}$ carbon domains $[25,35]$. Meanwhile, the ratio of intensity between D-band and G-band $\left(\mathrm{I}_{\mathrm{D}} / \mathrm{I}_{\mathrm{G}}\right)$ represented the degree of graphitization, a lower value means the higher degree of graphitization [25, 35]. All four of the samples present partial graphite characteristics, as shown in the spectra. The highest intensity ratio of the D-band versus the G-band $\left(\left(\mathrm{I}_{\mathrm{D}} / \mathrm{I}_{\mathrm{G}}\right)\right)$ of CSC-600 (1.01) and CSC-700 (0.96) means that these two samples contain more disordered carbon materials. While the $\mathrm{I}_{\mathrm{D}} / \mathrm{I}_{\mathrm{G}}$ values for CSC-800 and CSC-900 were 0.94 and 0.86 , respectively, suggesting that there was higher degree of graphitization in the AC sample prepared at higher temperature.

In order to investigate the amount of nickel present within the different carbons, surface element content of activated carbon samples were analyzed with energy-dispersive X-ray spectroscopy (EDS) in Scanning Transmission Electron Microscopy (STEM) mode. As is shown in Fig. S3(A-D), small amounts of Ni $(0.1 \%, 0.2 \%, 0.1 \%$ and $0.3 \%$ for CSC-600, CSC-700, CSC-800 and CSC-900, respectively.) and $\mathrm{K}(0 \%, 0.1 \%, 0.1 \%$ and $0.1 \%$ for CSC-600, CSC-700, CSC-800 and CSC-900, respectively.) still exist after hydrochloric acid hydrothermal treatments. These elements were remained in the AC matrix after acid treatment and deionized water wash. However, there is no significant patterns for these elements from XRD (Fig. 3A).

\subsection{Electrochemical performances of ACs}

Galvanostatic charge-discharge was used to test the performance of the supercapacitors based on the ACs. The charge-discharge time of CSC-700 (Fig. 4A) was longer than the chargedischarge time of CSC-600, CSC-800 and CSC-900 (Fig. S4). This proves that CSC-700 can be charged with more electrolyte ions than others, indicating the higher specific capacitance. Among these four supercapacitors, CSC-600 and CSC-700 present excellent capacitor characteristics in the lower current of $0.1 \mathrm{~A} \mathrm{~g}^{-1}$. However, CSC-600 does not show an excellent 
isosceles triangle curve. The voltage dropped sharply when the supercapacitor CSC-600 starts to discharge. It was caused by the lower pore diameter $(1.89 \mathrm{~nm}$, Table 1$)$, which would be the key factor affecting the electrolyte ion transportation [4]. The smaller pore diameter would prevent the ions from intercalating to the inner pore surface; that is to say, the electrolyte ions would need more time to migrate. Therefore, a voltage drop occurred for CSC-600 when it started to discharge.

The mesopore $(2-50 \mathrm{~nm})$ channels facilitate the transport of ions in the material, a noticeable volume of micropores $(<2 \mathrm{~nm})$ can provide abundant adsorbing sites for the ions [30]. CSC-600 and CSC-700 have more micropores $(<1.1 \mathrm{~nm})$ than CSC-800 and CSC-900, as is shown in Table 1. CSC-700 has more mesopores than CSC-600, which means the electrolyte ions can be faster to migrate in the porous structure of CSC-700 during the charge-discharge. Large surface area offers plentiful adsorbing sites for ions, CSC-700 shows high capability for charge accumulation at the electrode/electrolyte interface [36, 37].

The specific capacitances of the electrodes were calculated using galvanostatic chargedischarge analysis data at various constant current densities. As can be seen from Fig. 4B, the specific capacitance of CSC-600 decreased gradually with the increase of current density, which was concerned with the limited transportation of the electrolyte ions on the electrode surface during fast charging. Electrolyte ions do not have enough time to reach micropore surface at high current density, therefore the specific capacitance at high current density is lower than that at low current density [1]. However, it seems that CSC-700, CSC-800 and CSC-900 can be stable over a wider range of higher current densities, being $95.8 \%, 99.0 \%$ and $99.3 \%$ (from 0.5 to $5.0 \mathrm{~A} \mathrm{~g}^{-1}$ ) for CSC-700, CSC-800 and CSC-900, respectively. This phenomenon can be explained by the larger amount of mesopores from CSC-700 $\left(0.25 \mathrm{~cm}^{3} \mathrm{~g}^{-1}\right)$, CSC-800 $\left(0.63 \mathrm{~cm}^{3} \mathrm{~g}^{-1}\right)$ and CSC-900 
$\left(0.75 \mathrm{~cm}^{3} \mathrm{~g}^{-1}\right)$. These pores can support the accessibility of electrolyte ions into the active layer in the electrode matrix fast with higher current density.

The calculated specific capacitance of CSC-700 is $308 \mathrm{~F} \mathrm{~g}^{-1}$ at a current density of $0.1 \mathrm{~A}$ $\mathrm{g}^{-1}$, while the specific capacitance still exhibits relative high $\left(256 \mathrm{~F} \mathrm{~g}^{-1}\right)$ at a higher current density of $5.0 \mathrm{~A} \mathrm{~g}^{-1}$ with the retention of $83.1 \%$. These results indicate that CSC-700 is suitable for fast ion transportation. As an electrode material for supercapacitors, CSC-700 exhibits excellent electrochemical performance especially at high current density.

We compared our results with several other researchers who are looking for high quality carbon materials for supercapacitor. As Table 2 shows, the chemically modified graphene shows a specific capacitance of $135 \mathrm{~F} \mathrm{~g}^{-1}$ [38] and the graphene hydrogel presents $160 \mathrm{~F} \mathrm{~g}^{-1}$ [39]. The CVD generated carbon nanotube shows a specific capacitance of $75 \mathrm{~F} \mathrm{~g}^{-1}$ [40]. Even the $\mathrm{KOH}$ activated graphene only shows $150 \mathrm{~F} \mathrm{~g}^{-1}$ [41] at a current density of $1.0 \mathrm{~A} \mathrm{~g}^{-1}$. The high surface area AC produced from banana peel get high specific capacitance of $206 \mathrm{~F} \mathrm{~g}^{-1}$ at a current density of $1.0 \mathrm{~A} \mathrm{~g}^{-1}$ and it maintains for $190 \mathrm{~F} \mathrm{~g}^{-1}$ when the current density increased to $5.0 \mathrm{~A} \mathrm{~g}^{-}$ ${ }^{1}[20]$. The AC (CSC-700) we obtained from CSC shows high specific capacitance $\left(260 \mathrm{~F} \mathrm{~g}^{-1}\right.$ at a current density of $1.0 \mathrm{~A} \mathrm{~g}^{-1}$ and maintains $256 \mathrm{~F} \mathrm{~g}^{-1}$ at a current density of $5.0 \mathrm{~A} \mathrm{~g} \mathrm{~g}^{-1}$ ), which could be competitive as an electrode material for application in supercapacitors.

Cyclic voltammetry (CV) was performed to characterize the properties of the supercapacitors based on the various samples of AC. Fig. 5A indicates all samples exhibited a rectangular shape at slow sweep rates $\left(10 \mathrm{mv} \mathrm{s}^{-1}\right)$, suggesting all these porous structures are able to satisfy ion transfer/diffusion responses. However, with the increase of potential sweep rate (e.g., from 50 to $300 \mathrm{mV} \mathrm{s}^{-1}$ ), the CVs of CSC-600, CSC-700 and CSC-800 are distorted gradually from Fig. S5, while CSC-900 presents the best rectangular shape, even in very high 
scanning rate $300 \mathrm{mv} \mathrm{s}^{-1}$, which is attributed to the highly graphitized structure and large proportion of mesopores (interconnected and facilitated the electrolyte ion diffusion) from the carbon matrix. The high capacitance retention ratio can confirm the fast ion transport behaviors, as plotted in Fig. 5B. The specific capacitance is calculated accurately on the basis of the following equation [26]:

$$
C=\frac{2(1 / \Delta E) \int i d V / \mu}{m}
$$

Where $\mathrm{C}$ is the specific capacitance, $\mathrm{i}$ is the discharge current (A), $\Delta E$ is the voltage window, $\mathrm{V}$ is the voltage, $\mathrm{m}$ is the carbon mass of one electrode (g), and $\mu$ is the potential scan rate $\left(\mathrm{V} \mathrm{s}^{-1}\right)$. At $50 \mathrm{mV} \mathrm{s}^{-1}$, the ratio is as high as $88.9 \%$ for CSC-700 electrode, exceeding that of CSC-600 (85.5\%) and CSC-800 (88.4\%), while it is lower than CSC-900 (96.4\%). However, the retention ratio of CSC-700 is lower than CSC-800 at higher sweep rate (100, 200, and $300 \mathrm{mV} \mathrm{s}^{-}$ $\left.{ }^{1}\right)$. Therefore, CSC-700 might be a better choice for the electrode at low sweep rate, whereas CSC-800 is also a good option for electrode when using higher sweep rate. Among those samples, CSC-900 shows pretty high retention rate at the sweep rate ranged from 5 to $300 \mathrm{mV} \mathrm{s}^{-1}$, demonstrating the best ion transport.

Electrochemical impedance spectra (EIS) were obtained to further study the electrochemical properties of the carbon materials, and these were used to test the resistance of the supercapacitors. The Nyquist plots of the activated carbon in $6 \mathrm{M} \mathrm{KOH}$ electrolytes are shown in Fig. 5C, which shows the impedances over a frequency range of 0.1-200 $000 \mathrm{~Hz}$. For ideal porous electrodes, Nyqusit plot is a vertical straight line perpendicular to the horizontal coordinate. However, for real porous electrodes, Nyqusit plot can be separated into 3 parts: high frequency region, medium frequency region, low frequency region. In the high-frequency region, 
the Nyquist plot is semicircle and the real axis intercept is the equivalent series resistance (ESR). The width of the semicircle impedance loop represents charge transfer resistance in the electrode materials. As is shown in Fig. 5C, all the four curves have nearly the same first point of intersection with the horizontal axis, because all of the supercapacitors were using $6 \mathrm{M} \mathrm{KOH}$ as the electrolyte and the same assembly method was used for all four. It means that the resistance caused by the electrolyte and the contact resistance of these electrodes were similar. The second intersection points of the semicircles and the horizontal axis show the inner resistances (ESR) were smaller than $1.0 \Omega(0.65 \Omega$ for CSC-600 and CSC-800; $1.0 \Omega$ for CSC-700; $0.75 \Omega$ for CSC-900). In the low frequency region, the Nyqusit plot is a straight line for an EDLC. The more vertical the line is, the more ideal the capacitor is. It is shown that all ACs have almost vertical lines, indicating ideal capacitive behavior.

A long cycle life is another important concern for practical application of supercapacitors. The long term cyclic stabilities of the ACs were monitored by galvanostatic charge-discharge. As is shown in Fig. 6, the specific capacitance of CSC-700 was $323.0 \mathrm{~F} \mathrm{~g}^{-1}$ at the very beginning of the charge-discharge, then it gradually decreased to $287.5 \mathrm{~F} \mathrm{~g}^{-1}$ after 350 cycles (capacitance retention ratio of $89.0 \%$ ). This can be attributed to the existence of irreversible reactions at the beginning of the prolonged cycling (e.g. electro-oxidation, such as carbon oxidation) after which the values tend to stabilize [42]. Then the capacitance values remain practically constant for another 650 cycles. Even after 4000 cycles with different current density, it still remained at $287.5 \mathrm{~F} \mathrm{~g}^{-1}$ for another 500 cycles. Using the current density of $0.5,1.0$ and $5.0 \mathrm{~A} \mathrm{~g}^{-1}$ for 1000 cycles, it still maintained very good cyclic stability with capacitance retention ratio of $97.9 \%$ (from 265.0 to $262.4 \mathrm{~F} \mathrm{~g}^{-1}$ ), $98.6 \%$ (from 262.4 to $258.9 \mathrm{~F} \mathrm{~g}^{-1}$ ) and $98.8 \%$ (from 260.2 to $257.1 \mathrm{~F}$ $\mathrm{g}^{-1}$ ), respectively. The behaviors of CSC-600, CSC-800 and CSC-900 during long-term cycling 
are shown in Fig. S6. The trend of the cycle stability from CSC-600 is similar to CSC-700. There is also a decrease of capacitance during the first 350 cycles, then it maintained stable for the rest 650 cycles. However, CSC-800 and CSC-900 can maintain capacitance much better than CSC600 and CSC-700. Especially CSC-900 (174.5 $\left.\mathrm{F} \mathrm{g}^{-1}\right)$ can maintain $99.0 \%$ of the capacitance (176.2 $\mathrm{F} \mathrm{g} \mathrm{g}^{-1}$, with current density of $0.1 \mathrm{~A} \mathrm{~g}^{-1}$ ) after 4000 cycles. The coulombic efficiencies $(\eta)$ of the capacitors are also shown in Fig. S7, which are calculated according to

$$
\eta=\left(\frac{t_{D}}{t_{C}}\right) \times 100
$$

where $t_{D}$ and $t_{C}$ are the expressions of discharge and charge times [43], respectively. The results reveal that the supercapacitors have very stable coulombic efficiencies about $99 \%$ over 4000 cycles.

\section{Conclusion}

We have prepared high specific BET surface area activated carbon from CSC. Structural characterizations show that the CSC-700 has miro-meso hierarchical pore texture. Electrochemical measurements demonstrate that CSC-700 has excellent capacitive performance. The highest specific capacitance of CSC-700 is $323.0 \mathrm{~F} \mathrm{~g}^{-1}$ at a current density of $0.1 \mathrm{~A} \mathrm{~g}^{-1}$, while the specific capacitance still exhibits pretty high $\left(260.2 \mathrm{~F} \mathrm{~g} \mathrm{~g}^{-1}\right)$ at a higher current density

of $5 \mathrm{~A} \mathrm{~g} \mathrm{~g}^{-1}$. These results indicate that CSC-700 is suitable for fast ion transportation. As an electrode material for supercapacitors, CSC-700 exhibits excellent electrochemical performance especially at high current density.

\section{Acknowledgements}

This research was funded by following projects: 1) "Development of high value carbon based adsorbents from thermochemically produced biochar" USDA-NIFA 2011-67009-20030 
through the USDA-NIFA Agriculture and Food Research Initiative Sustainable Bioenergy Program which funded the Micropore analyzer and instruments for modifying AC; 2) NSF EPSCoR Track II Dakota BioCon center (National Science Foundation/EPSCoR Award No. 1330842) supported Mr. Cao Yuhe for his PhD study.

\section{Reference}

[1] X. Gao, W. Xing, J. Zhou, G. Wang, S. Zhuo, Z. Liu, Q. Xue, Z. Yan, Superior capacitive performance of active carbons derived from Enteromorpha prolifera, Electrochimica Acta, 133 (2014) 459-466.

[2] Y.Z. Wei, B. Fang, S. Iwasa, M. Kumagai, A novel electrode material for electric doublelayer capacitors, Journal of Power Sources, 141 (2005) 386-391.

[3] W. Zhang, Z.-H. Huang, G. Cao, F. Kang, Y. Yang, A novel mesoporous carbon with straight tunnel-like pore structure for high rate electrochemical capacitors, Journal of Power Sources, 204 (2012) 230-235.

[4] H. Jin, X. Wang, Z. Gu, J.D. Hoefelmeyer, K. Muthukumarappan, J. Julson, Graphitized activated carbon based on big bluestem as an electrode for supercapacitors, RSC Advances, 4 (2014) 14136.

[5] G. Wang, L. Zhang, J. Zhang, A review of electrode materials for electrochemical supercapacitors, Chemical Society Reviews, 41 (2012) 797-828.

[6] J.W. Jeon, S.R. Kwon, F. Li, J.L. Lutkenhaus, Spray-On Polyaniline/Poly(acrylic acid) Electrodes with Enhanced Electrochemical Stability, ACS applied materials \& interfaces, (2015).

[7] J. Yan, Q. Wang, T. Wei, Z. Fan, Recent Advances in Design and Fabrication of Electrochemical Supercapacitors with High Energy Densities, Advanced Energy Materials, 4 (2014) n/a-n/a. 
[8] A. Elmouwahidi, Z. Zapata-Benabithe, F. Carrasco-Marin, C. Moreno-Castilla, Activated carbons from $\mathrm{KOH}$-activation of argan (Argania spinosa) seed shells as supercapacitor electrodes, Bioresource technology, 111 (2012) 185-190.

[9] Y. Cao, K. Wang, X. Wang, Z. Gu, W. Gibbons, H. Vu, Adsorption of butanol vapor on active carbons with nitric acid hydrothermal modification, Bioresource technology, 196 (2015) $525-532$.

[10] Y. Cao, K. Wang, X. Wang, Z. Gu, W. Gibbons, H. Vu, Butanol vapor adsorption behavior on active carbons and zeolite crystal, Applied Surface Science, 349 (2015) 1-7.

[11] L.L. Zhang, X.S. Zhao, Carbon-based materials as supercapacitor electrodes, Chemical Society Reviews, 38 (2009) 2520-2531.

[12] A.G. Pandolfo, A.F. Hollenkamp, Carbon properties and their role in supercapacitors, Journal of Power Sources, 157 (2006) 11-27.

[13] X. Zhao, L. Wei, J. Julson, Z. Gu, Y. Cao, Catalytic cracking of inedible camelina oils to hydrocarbon fuels over bifunctional Zn/ZSM-5 catalysts, Korean Journal of Chemical Engineering, 32 (2015) 1528-1541.

[14] X. Zhao, L. Wei, S. Cheng, Y. Cao, J. Julson, Z. Gu, Catalytic cracking of carinata oil for hydrocarbon biofuel over fresh and regenerated Zn/Na-ZSM-5, Applied Catalysis A: General, 507 (2015) 44-55.

[15] I.I.G. Inal, S.M. Holmes, A. Banford, Z. Aktas, The performance of supercapacitor electrodes developed from chemically activated carbon produced from waste tea, Applied Surface Science, 357 (2015) 696-703.

[16] X. Li, W. Xing, S. Zhuo, J. Zhou, F. Li, S.Z. Qiao, G.Q. Lu, Preparation of capacitor's electrode from sunflower seed shell, Bioresource technology, 102 (2011) 1118-1123. 
[17] G. Ma, Q. Yang, K. Sun, H. Peng, F. Ran, X. Zhao, Z. Lei, Nitrogen-doped porous carbon derived from biomass waste for high-performance supercapacitor, Bioresource technology, 197 (2015) 137-142.

[18] Y. Fan, X. Yang, B. Zhu, P.-F. Liu, H.-T. Lu, Micro-mesoporous carbon spheres derived from carrageenan as electrode material for supercapacitors, Journal of Power Sources, 268 (2014) 584-590.

[19] X. He, P. Ling, J. Qiu, M. Yu, X. Zhang, C. Yu, M. Zheng, Efficient preparation of biomass-based mesoporous carbons for supercapacitors with both high energy density and high power density, Journal of Power Sources, 240 (2013) 109-113.

[20] Y. Lv, L. Gan, M. Liu, W. Xiong, Z. Xu, D. Zhu, D.S. Wright, A self-template synthesis of hierarchical porous carbon foams based on banana peel for supercapacitor electrodes, Journal of Power Sources, 209 (2012) 152-157.

[21] C. Zhong, S. Gong, L.e. Jin, P. Li, Q. Cao, Preparation of nitrogen-doped pitch-based carbon materials for supercapacitors, Materials Letters, 156 (2015) 1-6.

[22] J.-S. Lv, X.-Y. Liu, J.-X. Xu, Y.-F. Deng, Z. Wu, Y.-M. Wang, M.-Y. Fan, H. Xu, Preparation and properties of adsorption material from corn stalks core when used for enzyme immobilization and the subsequent activities of the adsorbed enzymes, Industrial Crops and Products, 50 (2013) 787-796.

[23] J. Sreńscek-Nazzal, W. Kamińska, B. Michalkiewicz, Z.C. Koren, Production, characterization and methane storage potential of $\mathrm{KOH}$-activated carbon from sugarcane molasses, Industrial Crops and Products, 47 (2013) 153-159.

[24] H. Jin, X. Wang, Z. Gu, Q. Fan, B. Luo, A facile method for preparing nitrogen-doped graphene and its application in supercapacitors, Journal of Power Sources, 273 (2015) 1156-1162. 
[25] K. Wang, Y. Cao, X. Wang, P.R. Kharel, W. Gibbons, B. Luo, Z. Gu, Q. Fan, L. Metzger, Nickel catalytic graphitized porous carbon as electrode material for high performance supercapacitors, Energy, 101 (2016) 9-15.

[26] Y. Gao, V. Presser, L. Zhang, J.J. Niu, J.K. McDonough, C.R. Pérez, H. Lin, H. Fong, Y. Gogotsi, High power supercapacitor electrodes based on flexible TiC-CDC nano-felts, Journal of Power Sources, 201 (2012) 368-375.

[27] K.S. Sing, Reporting physisorption data for gas/solid systems with special reference to the determination of surface area and porosity (Recommendations 1984), Pure and applied chemistry, 57 (1985) 603-619.

[28] J. Wang, S. Kaskel, KOH activation of carbon-based materials for energy storage, Journal of Materials Chemistry, 22 (2012) 23710.

[29] C. Vix-Guterl, E. Frackowiak, K. Jurewicz, M. Friebe, J. Parmentier, F. Béguin, Electrochemical energy storage in ordered porous carbon materials, Carbon, 43 (2005) 12931302.

[30] K. Xia, Q. Gao, J. Jiang, J. Hu, Hierarchical porous carbons with controlled micropores and mesopores for supercapacitor electrode materials, Carbon, 46 (2008) 1718-1726.

[31] A.C. Lua, T. Yang, Effect of activation temperature on the textural and chemical properties of potassium hydroxide activated carbon prepared from pistachio-nut shell, Journal of colloid and interface science, 274 (2004) 594-601.

[32] A. Dandekar, R. Baker, M. Vannice, Characterization of activated carbon, graphitized carbon fibers and synthetic diamond powder using TPD and DRIFTS, Carbon, 36 (1998) 18211831. 
[33] M. Liu, L. Gan, W. Xiong, F. Zhao, X. Fan, D. Zhu, Z. Xu, Z. Hao, L. Chen, Nickel-Doped Activated Mesoporous Carbon Microspheres with Partially Graphitic Structure for Supercapacitors, Energy \& Fuels, 27 (2013) 1168-1173.

[34] M. Liu, L. Gan, W. Xiong, Z. Xu, D. Zhu, L. Chen, Development of MnO2/porous carbon microspheres with a partially graphitic structure for high performance supercapacitor electrodes, Journal of Materials Chemistry A, 2 (2014) 2555-2562.

[35] J. Qi, L. Jiang, S. Wang, G. Sun, Synthesis of graphitic mesoporous carbons with high surface areas and their applications in direct methanol fuel cells, Applied Catalysis B: Environmental, 107 (2011) 95-103.

[36] M. Liu, J. Qian, Y. Zhao, D. Zhu, L. Gan, L. Chen, Core-shell ultramicroporous@microporous carbon nanospheres as advanced supercapacitor electrodes, J. Mater. Chem. A, 3 (2015) 11517-11526.

[37] Y. Zhao, M. Liu, L. Gan, X. Ma, D. Zhu, Z. Xu, L. Chen, Ultramicroporous Carbon Nanoparticles for the High-Performance Electrical Double-Layer Capacitor Electrode, Energy \& Fuels, 28 (2014) 1561-1568.

[38] M.D. Stoller, S. Park, Y. Zhu, J. An, R.S. Ruoff, Graphene-based ultracapacitors, Nano letters, 8 (2008) 3498-3502.

[39] Y. Xu, K. Sheng, C. Li, G. Shi, Self-Assembled Graphene Hydrogel via a One-Step Hydrothermal Process, ACS Nano, 4 (2010) 4324-4330.

[40] P. Lv, P. Zhang, F. Li, Y. Li, Y. Feng, W. Feng, Vertically aligned carbon nanotubes grown on carbon fabric with high rate capability for super-capacitors, Synthetic Metals, 162 (2012) 1090-1096. 
[41] Y. Chen, X. Zhang, H. Zhang, X. Sun, D. Zhang, Y. Ma, High-performance supercapacitors based on a graphene-activated carbon composite prepared by chemical activation, RSC Advances, 2 (2012) 7747.

[42] V. Ruiz, C. Blanco, R. Santamaría, J.M. Ramos-Fernández, M. Martínez-Escandell, A. Sepúlveda-Escribano, F. Rodríguez-Reinoso, An activated carbon monolith as an electrode material for supercapacitors, Carbon, 47 (2009) 195-200.

[43] W.-C. Chen, T.-C. Wen, Electrochemical and capacitive properties of polyaniline-implanted porous carbon electrode for supercapacitors, Journal of Power Sources, 117 (2003) 273-282. 
A

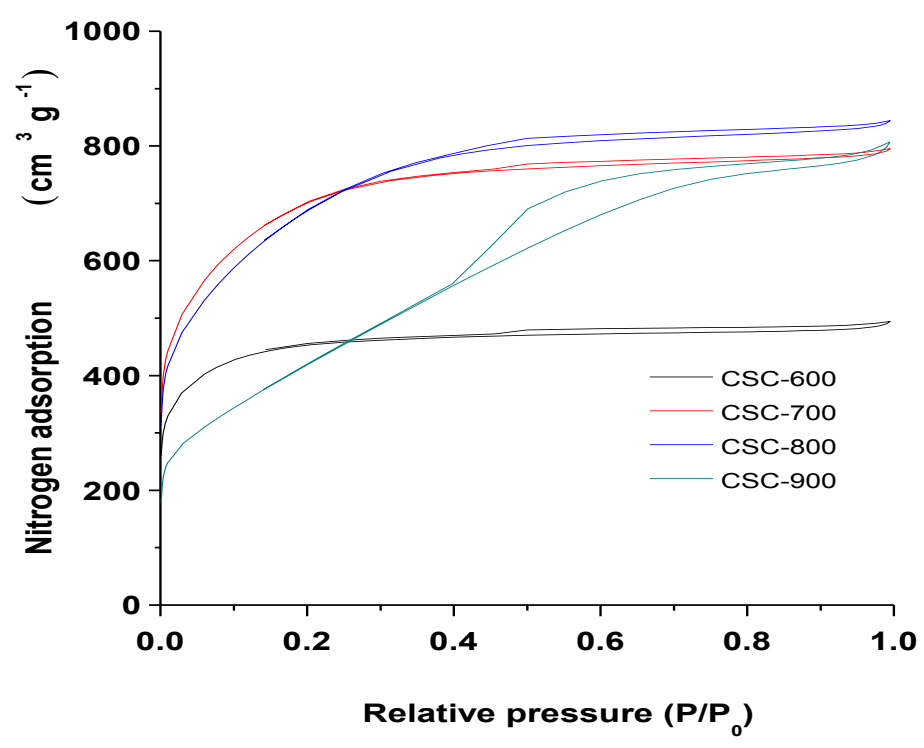

B

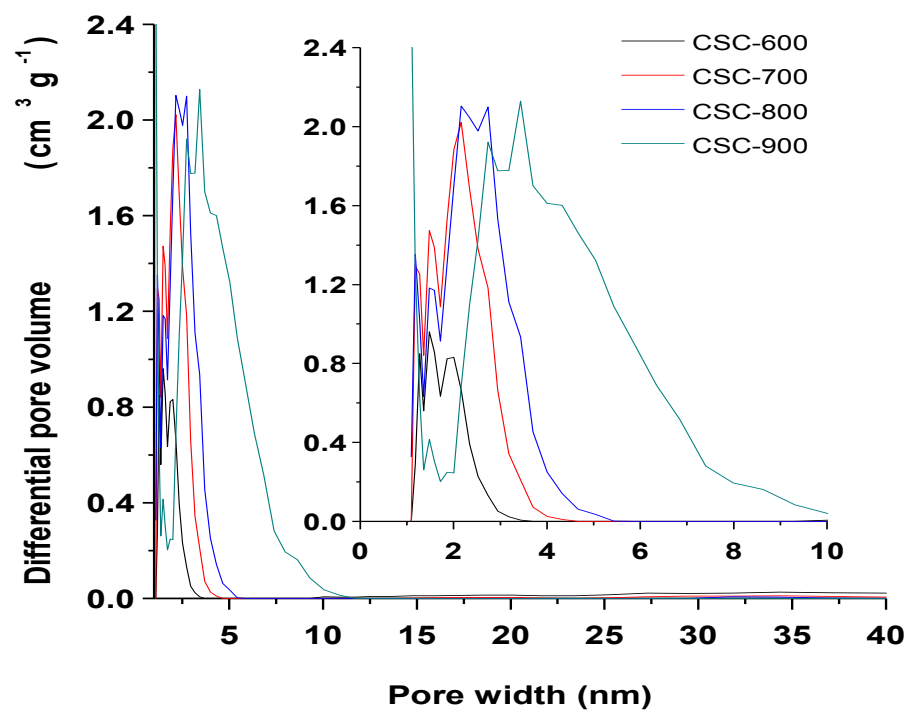

Fig. 1. (A) $\mathrm{N}_{2}$ isothermal adsorption/desorption on the ACs; (B) DFT pore size distribution curves of the ACs. 
A

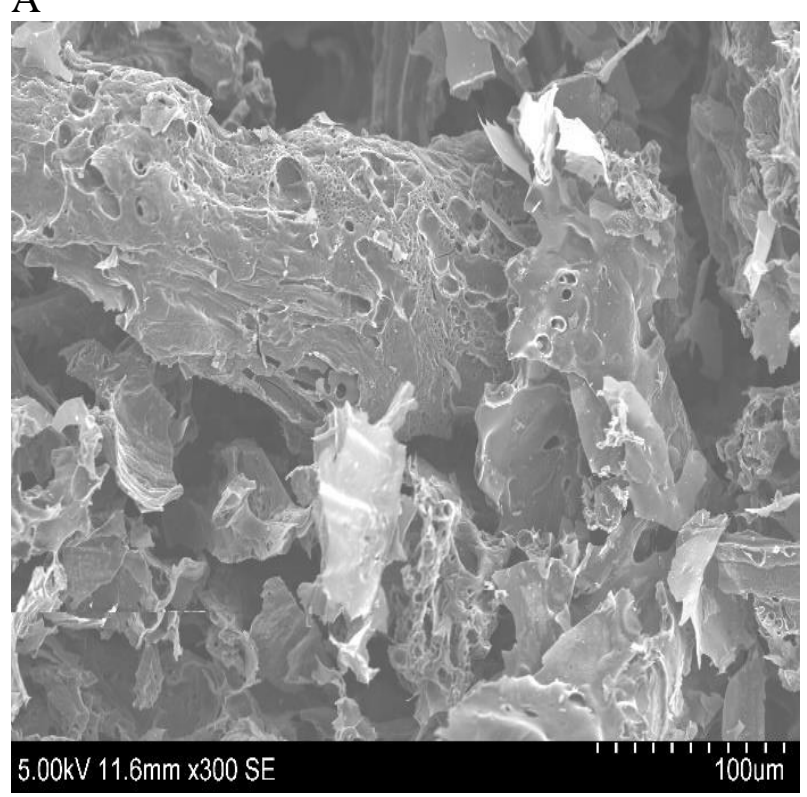

$\mathrm{C}$

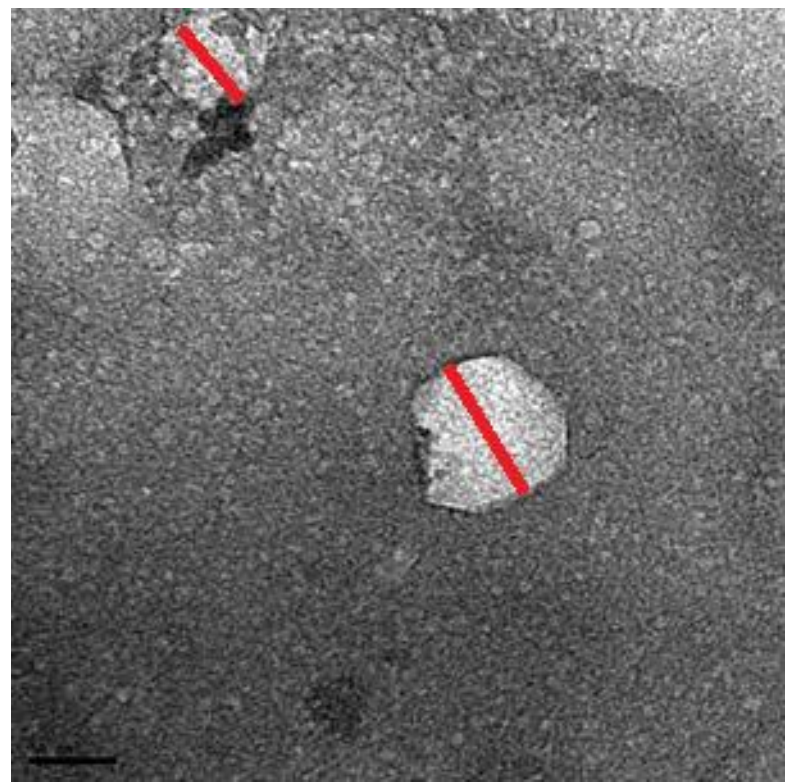

\section{B}

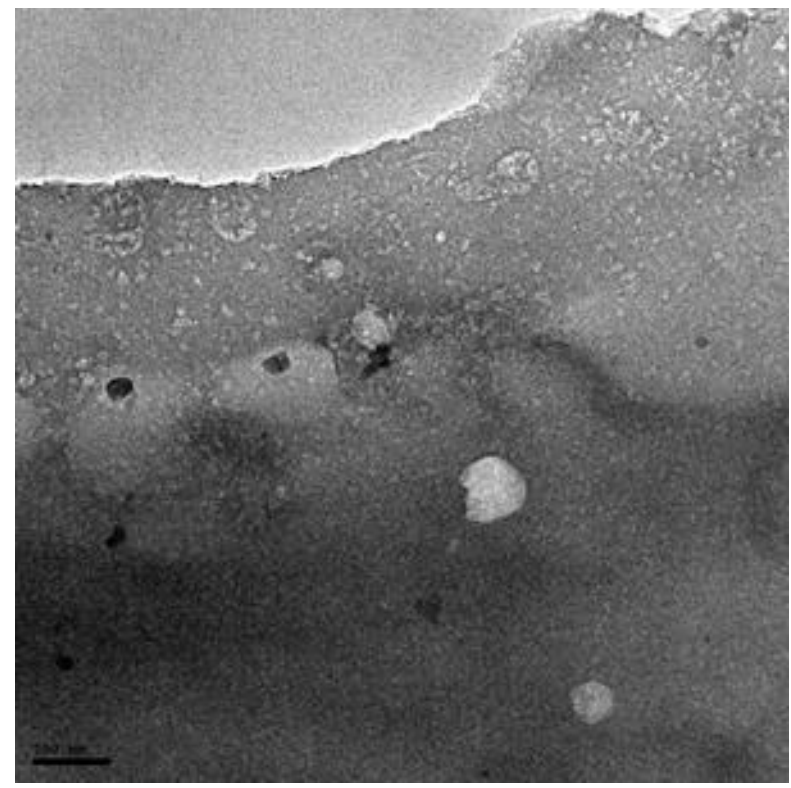

$\mathrm{D}$

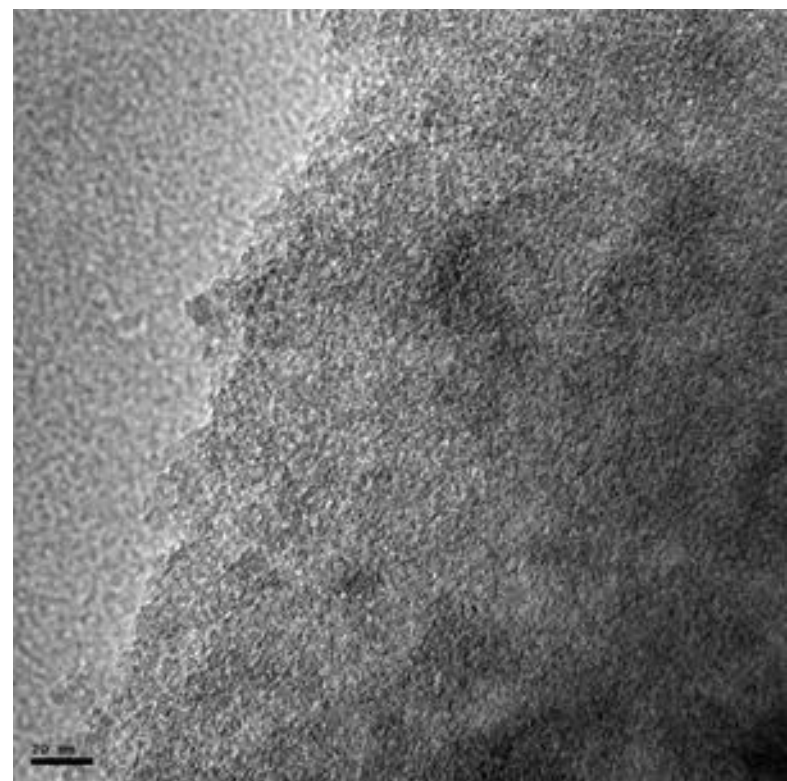

Fig. 2. Scanning electron microscopy image and transmission electron microscopy images of CSC-700. ( A) SEM image with a scale bar of $100 \mu \mathrm{m}$; (B) TEM image with a scale bar of 100 $\mathrm{nm}$; (C) TEM image with a scale bar of $50 \mathrm{~nm}$; (D) TEM image with a scale bar of $20 \mathrm{~nm}$; 
A

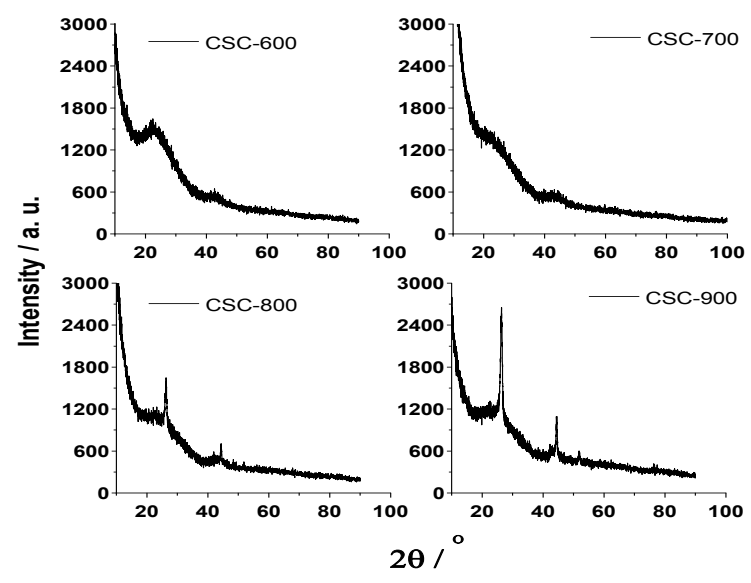

B

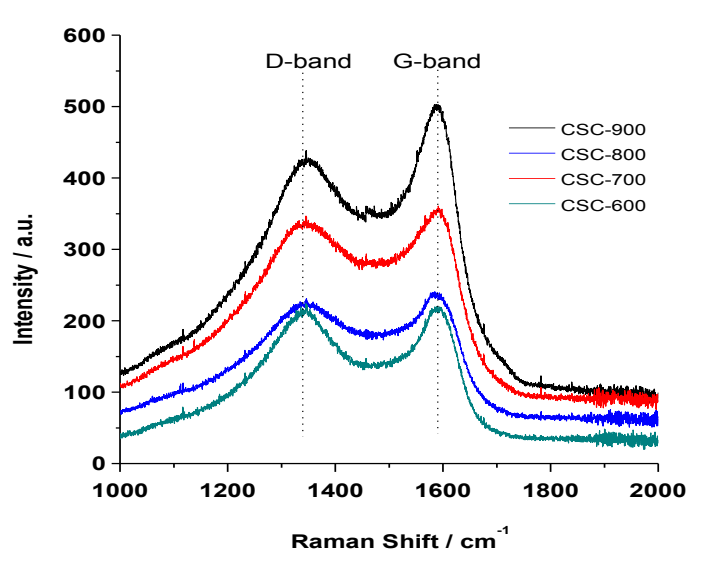

Fig. 3. (A) X-ray diffraction profiles of ACs; (B) Raman spectra of ACs. 
A

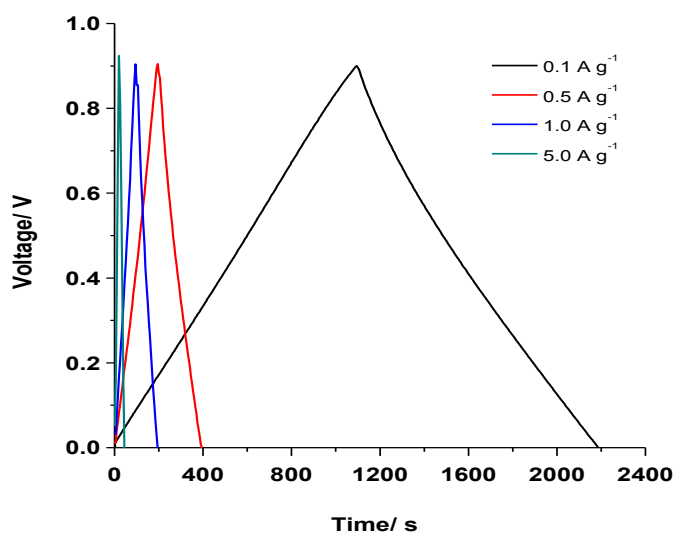

B

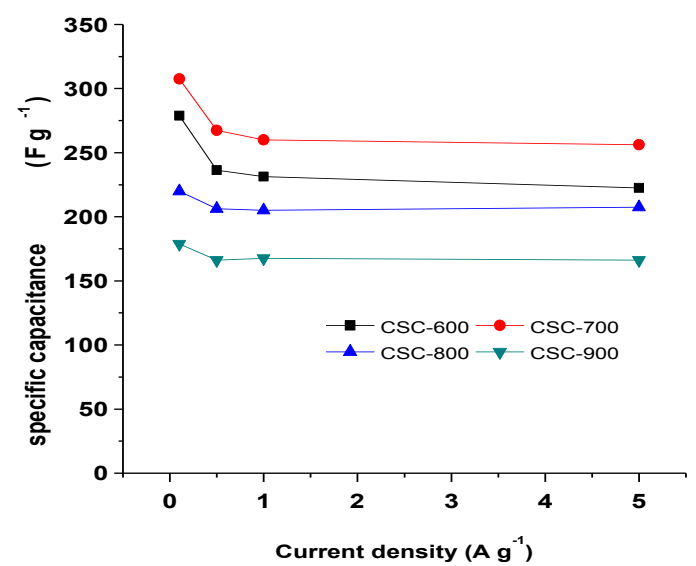

Fig. 4. (A) Galvanostatic charge/discharge results of CSC-700; (B) the relationship between the specific capacitance and current density. 
A

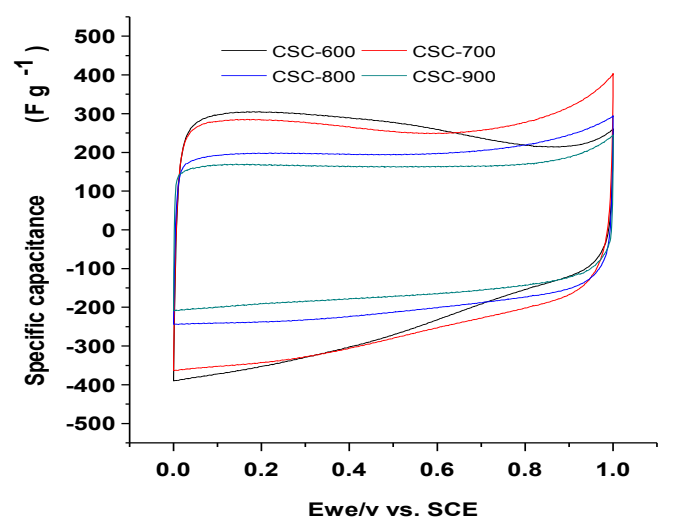

$\mathrm{C}$

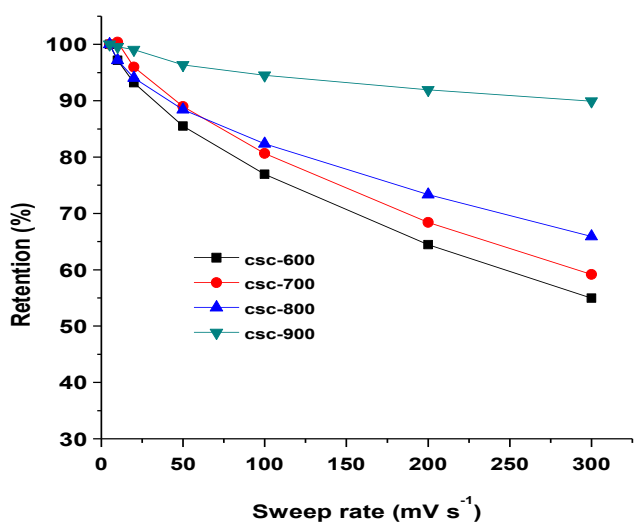

$\mathrm{B}$

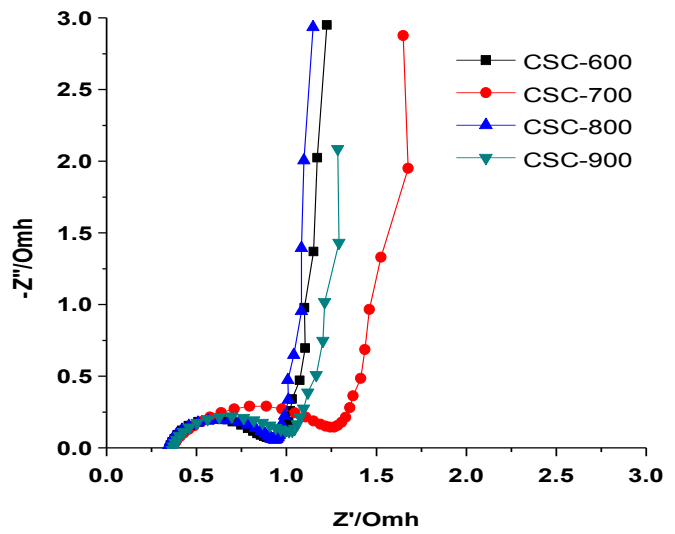

Fig. 5. Cyclic voltammograms and electrochemical impedance spectra (EIS) of AC electrodes. (A) The potential scan rate of $10 \mathrm{mV} \mathrm{s}^{-1}$; (B) the capacitance retention ratio as a function of potential sweep rate from 5 to $300 \mathrm{mV} \mathrm{s}^{-1}$; (C) Nyquist plots for the activated carbon in $6 \mathrm{M}$ $\mathrm{KOH}$ electrolytes recorded at room temperature. 


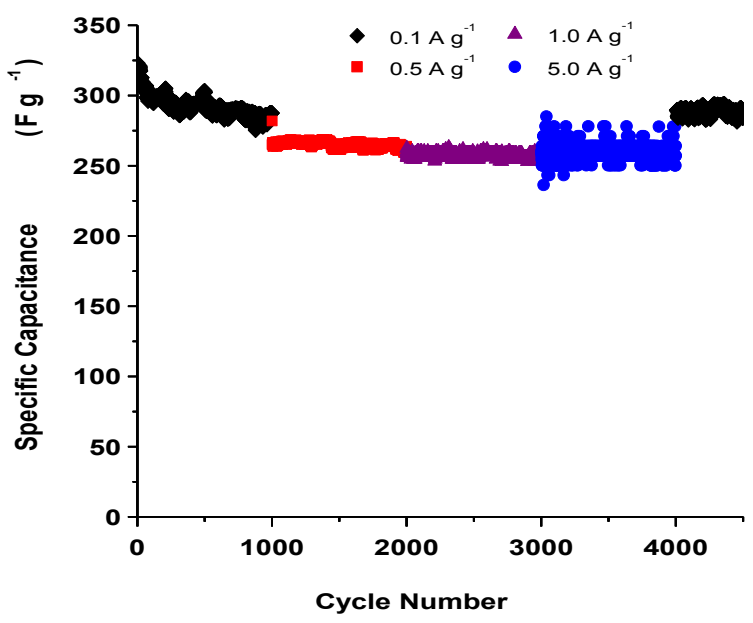

Fig. 6. The cycling performance of CSC-700 at the charge/discharge current of $0.1,0.5,1.0$ and $5.0 \mathrm{~A} \mathrm{~g}^{-1}$. 
Table 1 Surface area and pore structure parameters of the absorbents.

\begin{tabular}{lcccccc}
\hline Sample \# & $\begin{array}{c}\mathrm{S}_{\mathrm{BET}}{ }^{\mathrm{a}} \\
\mathrm{m}^{2} \mathrm{~g}^{-1}\end{array}$ & $\begin{array}{c}\mathrm{V}_{\text {Total }} \mathrm{b}^{3} \\
\mathrm{~cm}^{3} \mathrm{~g}^{-1}\end{array}$ & $\begin{array}{c}\mathrm{V}_{\text {Micro }} \mathrm{cm}^{3} \mathrm{~g}^{-1} \\
<1.1 \mathrm{~nm}\end{array}$ & $\begin{array}{c}\mathrm{V}_{\text {Meso }}{ }^{\mathrm{d}} \\
\mathrm{cm}^{3} \mathrm{~g}^{-1}\end{array}$ & $\begin{array}{c}\mathrm{D}_{\text {Average }} \mathrm{e} \\
\mathrm{nm}\end{array}$ \\
\hline CSC-600 & 1597 & 0.75 & 0.37 & 0.56 & 0.06 & 1.89 \\
CSC-700 & 2495 & 1.23 & 0.40 & 0.75 & 0.25 & 1.97 \\
CSC-800 & 2452 & 1.31 & 0.34 & 0.65 & 0.63 & 2.13 \\
CCS-900 & 1485 & 1.25 & 0.14 & 0.26 & 0.75 & 3.36 \\
\hline
\end{tabular}

${ }^{\text {a }}$ BET (Brunauer-Emmett-Teller) surface area

${ }^{\mathrm{b}}$ Total pore volume, measured at $\mathrm{P} / \mathrm{P}_{0}=0.995$

${ }^{c}$ Micropore volume, based on density functional theory (DFT)

${ }^{\mathrm{d}}$ Mesopore volume, based on density functional theory (DFT)

${ }^{\mathrm{e}}$ Average pore diameter of absorbents, calculated by $4 \mathrm{~V}_{\text {Total }} / \mathrm{S}_{\mathrm{BET}}$ 
Table 2 Specific capacitances comparison of different carbon materials.

\begin{tabular}{ccccc}
\hline Carbon resource & $\begin{array}{c}\text { Surface area } \\
\left(\mathrm{m}^{2} \mathrm{~g}^{-1}\right)\end{array}$ & $\begin{array}{c}\text { Capacitance F g } \\
\text { (electrolytes) }\end{array}$ & $\begin{array}{c}\text { Current density } \\
\mathrm{A} \mathrm{g}^{-1}\end{array}$ & Literature \\
\hline Graphene (Chemically modified) & 705 & $135(5.5 \mathrm{M} \mathrm{KOH})$ & 1.0 & {$[38]$} \\
Graphene hydrogel & -- & $160(5.0 \mathrm{M} \mathrm{KOH})$ & 1.0 & {$[39]$} \\
Carbon nanotube (CVD) & 212.8 & $75\left(1 \mathrm{M} \mathrm{H}_{2} \mathrm{SO}_{4}\right)$ & 1.0 & {$[40]$} \\
Graphene (KOH activation) & 798 & $150(6 \mathrm{M} \mathrm{KOH})$ & 1.0 & {$[41]$} \\
Banana peel (ZnNO 3 activation) & 1650 & $206(6 \mathrm{M} \mathrm{KOH})$ & 1.0 & {$[20]$} \\
Corn stalk core (KOH & & $190(6 \mathrm{M} \mathrm{KOH})$ & 5.0 & \multirow{2}{*}{ This } \\
activation) & 2495 & $260(6 \mathrm{M} \mathrm{KOH})$ & 1.0 & work \\
\hline
\end{tabular}

